\title{
A new data about the bottom sediments' structure of Lake Plescheevo (Yaroslavl region, Russia)
}

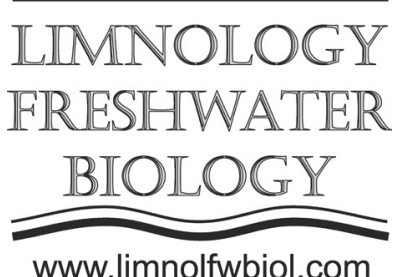

\author{
Rudinskaya A.I. ${ }^{1,2 *}$, Konstantinov E.A. ${ }^{1}$, Gedminienė L. ${ }^{3}$, Vaikutienè G. ${ }^{4}$ \\ ${ }^{1}$ Institute of Geography, Russian Academy of Sciences, Staromonetny L., 29/4, Moscow, 119017, Russia \\ ${ }^{2}$ Faculty of Geography, Moscow State University, Leninskiye Gory Str., 1, Moscow, 119991, Russia \\ ${ }^{3}$ Geology and Geography Institute, Nature Research Center, Akademijos Str. 2, LT-08412 Vilnius, Lithuania \\ ${ }^{4}$ Faculty of Chemistry and Geoscience, Vilnius University, Naugarduko g. 24, LT-03225, Vilnius, Lithuania
}

\begin{abstract}
A complex of field, laboratory and analytical and cameral works was carried out to reconstruct the Holocene history of Lake Plescheevo. We drilled the bottom sediments and got six cores from the different parts of the lake. The grain size analysis, LOI and magnetic susceptibility measurement, geochemical and diatom analysis were carried out. The structure and composition of sediments are related to the depth of the lake. At depths up to 15-18 m deposits are represented by the layered sandy-loamy sediments, practically devoid of organic components, at depths greater than $18 \mathrm{~m}$ there are organic mineral silt. Geochemical composition shows strong changes for deposits from the depth $60-0 \mathrm{~cm}$. The diatom analysis shows small decrease in level while maintaining deep water conditions.
\end{abstract}

Keywords: Lake Plescheevo, sediment archives, Holocene, paleoinvironment

\section{Introduction}

One of the most complete environmental characteristics of the Lake Plescheevo is based on materials collected in the 1980s (Ecosystem ..., 1989). In recent years, the seismic profiling and some drilling gave a more detailed description of the underwater relief of the lake basin and its component sediments (Krylov, 2018). There are some reconstructions of the paleoenvironmental dynamics of the lake during the Holocene based on the distribution of magnetic minerals and organic matter (Gapeeva et al., 2005) and diatom analysis (Palagushkina et al., 2018). However, a detailed study of the differences in the structure of bottom sediments on various underwater relief has not been carried out previously.

\section{Material and methods}

Drilling were carried out in three areas: 1) a profile through underwater terraces on the eastern side (four cores, each 3-3.5 m long); 2) an underwater terrace on the west side (a 3.85 m-long core); 3) the northwestern part of the deep axial hollow (two cores samples from the depths of $0.0-2.7 \mathrm{~m}$ and $1.2-4.0 \mathrm{~m}$ ). The first and the second areas were drilled by the Livingston piston sampler; the third area was drilled by the Nesje piston sampler. The grain size analysis, LOI and magnetic susceptibility measurement were carried out. The grain size analysis was performed by the laser diffractometry using the Malvern Mastersizer 3000 Particle Size Analyzer. Diatom and geochemical analysis were performed for the column PLESH-4.2 to a depth of $260 \mathrm{~cm}$ (this column is from the deepest part of the lake). For the geochemical analysis in total 33 elements were determined by EDXRF equipment Spectro Xepos using the Turboquant for the pressed pellet calibration procedure elaborated by the manufacturers (Schramm, Heckel, 1998). Slides for diatom analysis were prepared using standart procedures (Batarbee et al., 2001) for the intervals $2 \mathrm{~cm}$ with the step $10 \mathrm{~cm}$. More than 1000 valves in each slide were identified.

\section{Results}

The structure of the underwater terrace (depth 5-8 $\mathrm{m}$ ) of the eastern side of the lake was discovered. The terrace is represented by the layered sandy-loamy deposits, practically devoid of organic components. In the deep central part of the lake sediments are represented by organic-mineral silt with an organic matter content from 18 to $32 \%$. The clay-aleurite fraction predominates in the particle size distribution, in the depths more than $60 \mathrm{~cm}$ the content of the fine sand increases to $10 \%$. According to Palagushkina et al. (2018), the maximum age of the $260 \mathrm{~cm}$ column is about 3000 years BP. The analysis of the lithological

*Corresponding author.

E-mail address: rudinskaya94@gmail.com (A.I. Rudinskaya) 
composition illustrates the trends in variations which, together with statistical data, allow revealing 6 lithological - geochemical units, which at about $60 \mathrm{~cm}$ subdivides in two major groups. The first major group, that cover 260-60 cm sediment interval, includes relatively more stable elemental composition that is mostly reflected by stable $\mathrm{Si}$. All that time lake bottom layers were less oxidant, with very low variation. The second major group, that cover $60-0 \mathrm{~cm}$ of the sediment column, includes two ChEAZ, which has very variable data, especially for $\mathrm{Ca}, \mathrm{Sr}, \mathrm{Pb}$, and $\mathrm{Cl}$. The diatom analysis shows two LDAZ: the $260-90 \mathrm{~cm}$ interval gives the predominance of planktonic species (Aulacoseira granulata, Stephanodiscus alpinus, Stephanodiscus neoastrea), the $90-0 \mathrm{~cm}$ interval shows noticeable growth of the perithytic species (Pseudostaurosira brevistriata, Staurosirella martyi) up to $30 \%$, although the predominance of planktonic species remains.

\section{Discussion}

The sediment structure of the underwater terrace indicates an intensive supply of terrigenous material to the coastal part of the lake bottom. The sediment from the central deepwater part of the lake, on the contrary, related to the stable sedimentation conditions. Variability of the geochemical composition of the upper part of the sediments could be caused by:

1. lowering of the water table;

2. the change of the sedimentation source, maybe main inflows could have changed their debit, wind the direction;

3. shores became protected by growing plants, and therefore more humics and nutrition reached the lake.

Prevailing of planktonic acidophilic cold-loving diatoms species throughout the column indicate stable deep-water sedimentation conditions. However, a slight increase in periphyton species at depths of $2-90 \mathrm{~cm}$ could be caused by lowering in water level while maintaining significant depths and cold winter conditions.

\section{Conclusion}

This study allows us to establish different sedimentation conditions in the Lake Plescheevo in the second half of the Holocene: stable conditions in deep central part and intense supply of terrigenous material was intensively supplied to the coastal parts

\section{References}

Battarbee R.W., Jones V.J., Flower R.J. 2001. Diatoms. In: Smol J.P,Birks H.J-B. and Last W.M. (Eds.) Tracking Environmental Change Using Lake Sediments. Terrestrial, Algal and Siliceous Indicators, pp.155-202.

Ecosystem of Lake Plescheevo. 1989. In: Butorin N.V., Skljarenko V.L. (Eds). Leningrad: Nauka. (in Russian)

Gapeeva M.V., Nurgaliev D.K., Sigareva L.E., Hides I. 2005. Historical trends of nutrients in the bottom sediments of the Pleshcheyevo Lake under natural and anthropogenic conditions. Ecologicheskaya Khimiya [Ecological Chemistry] 4: 55-62. (in Russian)

Krylov, 2018. Seismic acoustics of modern lakes' bottom deposits as the basis paleogeophysical and paleoclimatic reconstruction. PhD Thesis, Kazan Federal University, Russian Federation. (in Russian)

Palagushkina O., Frolova L., Zinnatova E. et al. 2018. Diatoms of sediments of Plescheevo Lake (Russia) as indicators of environmental changes in Holocene. In: $18^{\text {th }}$ International Multidisciplinary Scientific Geoconferense, pp.283-288.

Schramm, R., Heckel, J. 1998. Fast analysis of traces and major elements with ED (P) XRF using polarized X-rays: TURBOQUANT. Journal de Physique [Physics Journal] 8(PR5): 335-342. 